\title{
Retraction Note to: Modeling and design of Magnetic Tunneling Junction using MoS2/graphene quantum dots/ MoS2 approach
}

\author{
Swapnali Makdey • Rajendra Patrikar • \\ Mohammad Farukh Hashmi
}

Published online: 21 February 2022

C) Springer Nature B.V. 2022

\section{Retraction Note to: J Nanopart Res (2020) 22:212 https://doi.org/10.1007/s11051-020-04920-9}

The Editor-in-Chief and the Publisher have retracted this article. The article was accepted as part of a guest-edited special issue in Journal of Nanoparticle Research. Before the special issue was finalized, the Editor-in-Chief detected problems with editorial handling and peer review and decided not to proceed with the special issue [1].

Post publication peer review found that this article is out of scope for the journal, which focuses on original contributions on nanoscale phenomena and processes, and does not meet the standards required by the journal. None of the authors have responded to any correspondence from the Editor and Publisher about this retraction.

The original article can be found online at https://doi.org/ 10.1007/s11051-020-04920-9

\section{S. Makdey $\cdot$ R. Patrikar}

Centre for VLSI and Nanotechnology, Visvesvaraya

National, Institute of Technology, Nagpur, India

e-mail: swapnali@frcrce.ac.in

R. Patrikar

e-mail: rajendra@computer.org

\section{F. Hashmi $(\bowtie)$}

Department of Electronics and Communication Engineering, National Institute of Technology, Warangal, India

e-mail: mdfarukh@nitw.ac.in

\section{References}

Pinna N, Clavel G, Roco MC (2020) The Journal of Nanoparticle Research victim of an organized rogue editor network! J Nanopart Res 22:376. https://doi.org/10.1007/ s11051-020-05094-0

Publisher's note Springer Nature remains neutral with regard to jurisdictional claims in published maps and institutional affiliations. 